Magdalena Dutsch-Wicherek ${ }^{1,2}$, Agata Lazar ${ }^{3}$, Romana Tomaszewska ${ }^{3}$, Kornelia Kliś ${ }^{4}$, Konrad Dziobek ${ }^{5}$, Łukasz Wicherek ${ }^{6}$

${ }^{1}$ Uniwersytet Jagielloński Collegium Medicum Uniwersytecki Szpital Dziecięcy, Kraków, Poland

${ }^{2}$ Centrum Onkologii w Bydgoszczy, Bydgoszcz, Poland

${ }^{3}$ Department of Pathology, Jagiellonian University, Kraków, Poland

4Jagiellonian University Medical College, Faculty of Medicine, Kraków, Poland

${ }^{5}$ Department of Gynecological Oncology Lukaszczyk Oncological Center in Bydgoszcz, Poland

${ }^{6}$ Chair of Oncology, Radiotherapy and Gynecological Oncology, Ludwik Rydygier Collegium Medicum in Bydgoszcz, Nicolaus Copernicus

University, Bydgoszcz, Poland

\title{
RCAS1 and B7H4 \\ antigens immunoreactivity in squamous cell carcinoma of palatine tonsils and cancer microenvironment
}

\author{
Corresponding author: \\ Magdalena Dutsch-Wicherek \\ Uniwersytet Jagielloński \\ Uniwersytecki Szpital Dziecięcy, \\ Collegium Medicum, \\ Wielicka 265 St \\ 30-663 Kraków, Poland \\ e-mail:mowicher@gmail.com \\ Medical Research Journal 2018; \\ Volume 3, Number 3, 134-141 \\ 10.5603/MRJ.2018.a0022 \\ Copyright (C) 2018 Via Medica \\ ISSN 2451-2591
}

\begin{abstract}
B7-H4 protein has been demonstrated to be over-expressed by various types of cancer cells. The level of expression of $\mathrm{B} 7-\mathrm{H} 4$ in these cancers is related to the type of cancer, its stage, and the number of Treg cells, and correlates with patient survival and might be a new therapeutic target. The major role of RCAS1 expression is to inhibit activated immune cells, such as T and B lymphocytes and NK cells, and to induce their apoptosis. It has also been postulated that RCAS1 is involved in the remodelling of the tumour microenvironment.

The aim of the present study has been to evaluate RCAS1- and B7-H4-antigen immunoreactivity in squamous cell carcinoma of the palatine tonsils and in the cancer microenvironment. For our study, we recruited 30 patients with primary squamous cell carcinoma originating from the palatine tonsils.

Key words: B7H4, RCAS1, cancer microenvironment, tonsillar cancer
\end{abstract}

Med Res J 2018; 3 (3): 134-141

\section{Results}

B7-H4 antigen was over-expressed in cancerous tonsillar tissue and was significantly higher in those patients with the presence of lymph node metastases. The immunoreactivity of $\mathrm{B} 7-\mathrm{H} 4$ in the cancerous tumour microenvironment was represented by macrophages and cancer-associated fibroblasts and was statistically significantly associated with the presence of lymph node metastases. RCAS1 antigen over-expression was identified in palatine tonsil squamous cell carcinoma cells and associated with the presence of lymph node metastases.

\section{Conclusions}

Our study seems to indicate that both RCAS1- and B7-H4- immunopositive macrophages, together with B7H4 immunopositive cancer-associated fibroblasts, may play an important role in creating the suppressive profile of the tumour microenvironment of patients with tonsillar cancer.

\section{Introduction}

For a long time, it has been recognized by various pathologists that the tumour-associated inflammatory response promotes tumorigenesis as well as the progression of cancer. The presence of an aggressive tumour phenotype is related to the local infiltration of cancer cells and the potential to develop lymph node metastases. This phenotype is also associated with the intensity of creating the suppressive profile of the tumour microenvironment or the tumour cells that create the cancer microenvironment. This microenvironment determines the growth and progression of a tumour and initiates the ability to metastasize. The tumour stroma is infiltrated by immune system cells which represent 
the phenotype that supports tumour growth, such as tumour-associated macrophages (TAMs). It has been demonstrated that the suppressive phenotype of macrophages is linked with the expression of such membrane proteins as RCAS1 and HLA-G [1-4]. The local invasion of cancer is associated with the process of cancer stroma remodelling and the epithelial to mesenchymal transition. During this process, the stromal fibroblasts change their phenotype into cancer-associated fibroblasts (CAFs). This change is related to different protein expression profiles. Recently, both RCAS1 and B7-H4 antigens have been observed to be expressed by CAFs and been associated with the clinical outcome of the disease [3, 5-7].

The $\mathrm{B} 7-\mathrm{H} 4$ molecule belongs to the $\mathrm{B} 7$ molecule family, which includes CD80 and CD86 along with the receptors CD28 and cytotoxic T-lymphocyte antigen (CTLA-4). Its major role is to provide positive and/or negative co-signalling at the initiation stage of T-cell responses, in conjunction with a T-cell receptor (TCR)-mediated antigenic signal. B7-H4 mRNA is expressed in APCs, including brain, thymus, heart, lung, liver, stomach, intestinal tract, pancreas, prostate, ovary, placenta, urethra, skin, muscle, and bone cells [8]. Tumour-associated CD4+CD25+forkhead box p3 (Foxp3) + Treg cells can trigger APCs, including macrophages, to produce both IL-6 and IL-10 (38). These cytokines stimulate macrophage expression of B7-H4, whereas GM-CSF and IL-4 inhibit it [7]. Interestingly, since IL-4, IL-6, IL-10, and GM-CSF have not been found to regulate $\mathrm{B} 7-\mathrm{H} 4$ expression on tumour cells, the B7-H4 expression on these cells may be functionally distinct from that on APCs and may be differentially regulated. In accord with this, both Treg cells and macrophage $\mathrm{B} 7-\mathrm{H} 4$, but not tumour $\mathrm{B} 7-\mathrm{H} 4$, have been negatively associated with patient outcome. B7-H4+ tumour macrophages may be a novel suppressor cell population in ovarian cancer that can be therapeutically targeted [8-12].

In recent studies, B7-H4 protein has been demonstrated to be over-expressed by various types of cancer cells. The level of expression of B7-H4 in ovarian cancer, for example, is related to the type of cancer, its stage, and the number of Treg cells, and correlates with patient survival. In oral squamous cell carcinoma, B7-H4 was highly expressed, and the B7-H4 expression level was associated with the clinicopathological parameters of the patient's cancer, such as the pathological grade and lymph node status. It was observed that patients with high B7-H4 expression had poorer overall survival compared with those patients with low B7-H4 expression. It was also suggested that $\mathrm{B} 7-\mathrm{H} 4$ may be a potential target in the treatment of oral squamous cell carcinoma [12].

The major role of RCAS1 expression is to inhibit activated immune cells, such as $T$ and $B$ lymphocytes and NK cells, and to induce their apoptosis. RCAS1 is therefore responsible for tumour escape from the host immunological surveillance and the creation of immune tolerance for tumour cells [13-16]. The RCAS1 expression has been found in various malignant neoplasms and is related to the grade of the tumour, the stage of cancer, and the presence of lymph node metastases, as well as to a poorer prognosis. It has also been postulated that RCAS1 is involved in the remodelling of the tumour microenvironment in cases of uterine cervical cancer [17-20].

The aim of the present study has been to evaluate RCAS1- and B7-H4-antigen immunoreactivity in squamous cell carcinoma of the palatine tonsils and in the cancer microenvironment (including stromal fibroblasts and the macrophages infiltrating the tumour) and to analyze its relation to both clinical and pathological parameters.

\section{Materials and methods}

\section{The group of patients}

For our study, we recruited patients with primary squamous cell carcinoma originating from the palatine tonsils and selected 30 of them. In each of these patients, tissue samples were taken from both the carcinoma and the tumour microenvironment and then analyzed. The microenvironment, or stroma of the tumour, is defined as the surrounding $1 \mathrm{~cm} 2$ of tissue that is macroscopically and histologically free of cancer infiltration.

For all patients, radical surgery of the tumour was performed along with lymphadenectomy. The patient's consent was obtained in each case. Additionally, approval for the research program was granted from the Ethical Committee of the Jagiellonian University in Krakow: KBET/90/B/2005.

All the tissue samples were histopathologically verified. Pathological analysis, using the classical hematoxylin and eosin staining techniques after fixation in a formalin of the surgically removed material, was performed in the Pathology Department of the JagielIonian University by two experienced pathologists (R.T. and A.L.) working independently. The tissue material was then fixed in the solution of $10 \%$ formalin, rinsed, dehydrated, and transferred through a progressively increasing concentration of ethanol (from 50\% to absolute alcohol); it was then passed through xylens I, II, and III as well as molten paraffin wax. Lastly, the tissue blocks were sectioned and placed onto 3-4 mm slides. The process was mainly automated, but both the paraffin embedding and the sectioning of the tissue samples into 3-4 $\mathrm{mm}$ slides were performed manually. Table 1 presents the characteristics of the patient group. 
Table 1. The characteristics of the patient group

\begin{tabular}{lc}
\hline Squamous cell carcinoma of the palatine tonsil \\
\hline The number of patients & 30 \\
$M^{*}$ & 24 \\
W $^{*}$ & 6 \\
Age average & $46-7055.7$ \\
$M^{*}$ & $46-7057.3$ \\
$W^{*}$ & $47-6255.3$ \\
Stage & \\
I & 1 \\
II & 9 \\
III & 16 \\
IV & 4 \\
The presence of lymph node metastases & \\
N0 & 24 \\
N+ & 6 \\
Tumour size & \\
T1 & \\
T2 & 5 \\
T3 & 16 \\
T4 & 7 \\
Tumour grading & 2 \\
G1 & \\
G2 & 2 \\
G3 & 18 \\
*Abbviti & 10 \\
\hline
\end{tabular}

*Abbreviations: $\mathrm{M}$ - men, $\mathrm{W}$ - women

Table 2. The characteristics of the reference group

\begin{tabular}{lc}
\hline Palatine tonsils & \\
\hline The number of patients & 20 \\
$M^{*}$ & 10 \\
$W^{*}$ & 9 \\
Age range average & $17-5631.3$ \\
$M^{*}$ & $21-5432.5$ \\
$W^{*}$ & $17-5626.8$
\end{tabular}

*Abbreviations: $\mathrm{M}$ - men, $\mathrm{W}$ - women

\section{Reference group}

As a reference group, we chose to collect palatine tonsils that had been removed from patients due to recurrent tonsillitis. In these tissue samples, we evaluated the epithelium lining of the tonsils rather than the lymphoid tissue. The characteristics of the reference group are presented in Table 2.

\section{Immunohistochemical analysis}

In the present study, we aimed to analyze the immunoreactivity levels of various antigens in squamous cell carcinoma of the palatine tonsils and their stroma. We were also interested in the distribution of the antigen immunoreactivity throughout the tissue of a whole tumour, including the stroma. For this reason, we chose the immunohistochemistry method for the present study. This is the only method that shows the actual architecture of the dialogue between a tumour and its stroma.

Three to four tissue samples were taken from each tumour, depending on the tumour size (if, for instance, the tumour was $1 \mathrm{~cm}$ in diameter, then it was subject to further analysis). Each tissue sample was embedded in paraffin and formed into a tissue block which was then cut into tissue slides. All the tissue slides were further histopathologically verified and for the additional analysis, the most representative slides were selected to undergo immunohistochemistry (for the analysis of both a tumour and the stromal samples and in order to assess the tumour-stroma interaction).

Immunohistochemical analysis was performed in the Pathology Department of the Jagiellonian University. Five-micrometre slides from each case were deparaffinized, rehydrated, and rinsed in distilled water. Endogenous peroxidase activity was blocked by 8 minutes of incubation in $3 \% \mathrm{H} 2 \mathrm{O} 2$ at room temperature. The slides were then rinsed and immersed in a boiling citrate buffer ( $\mathrm{pH}$ 6.0) in a microwave oven with three changes of buffer for 5 minutes each. In each case, immunohistochemistry was performed applying the Envision method using DakoAutostainer. The samples were stained automatically. The immunohistochemical staining was based on antigen-antibody reaction. Microscopy was performed using an Axio Zeiss microscope, and the tissue slides were then evaluated under both $20 x$ and 40x magnification.

Four-micrometer sections from each case, mounted on organosilane-pre-treated slides, were stained to visualize the expression of both $\mathrm{B} 7-\mathrm{H} 4$ and RCAS1 in the various components: cancer cells, stromal cells (fibroblasts), and the cells of the inflammatory infiltrate reactive to cancer, including macrophages (macrophages are characterized by vesicular nuclei and distinct, relatively abundant cytoplasm). Previous immunostains with lineage-specific antigen CD68 for visualization of these cells (CD68, clone PG-M1;DAKO Denmark A/S, dilution 1:50, incubation for 30 minutes, after antigen retrieval in EDTA ph 8.0) proved helpful; the level of CD68 immunoreactivity directly corresponds with the number of macrophages identified by their morphological feature.

Prior to the application of the primary antibody, the slides for B7-H4 staining were incubated three times for 15 minutes in hydrogen peroxide plus absolute methanol to block endogenous peroxidase and submitted to $3 \%$ low-fat dried milk diluted 1:100 in PBS to perform the non-specific binding. For antigen retrieval, the sections were immersed in $10 \mathrm{mM}$ sodium citrate buffer, pH 6.2. The primary antibody, B7-H4 Antibody, rabbit polyclonal (Abbiotec; LLC, San Diego, CA, USA, Catalog No. 259473, for research only) was applied 
in dilution 1:100. The slides were incubated with the primary monoclonal antibody in a humidified chamber for $1 \mathrm{hr}$ at room temperature.

For RCAS1 immunostaining, the slides were prepared in the same manner as mentioned above and submitted to immunohistochemical assay for the mouse monoclonal antibody Anti-RCAS1 (Medical and Biological Laboratories, Naka-ku Nagoya, Japan in DAKO Antibody Diluent with Background Reducing Components-DAKO, Glostrup, Denmark, dilution 1:1000) in the humidified chamber overnight. A semi-quantitative interpretation of immunohistochemical results was carried out by two observers, who, working independently of each other and having no knowledge of the clinicopathological data, reviewed the immunohistochemical expression of the B7-H4 antigen, RCAS1 antigen, and CD68-positive cells.

An average number of B7-H4- and RCAS1-antigen positive macrophages and fibroblasts (identified morphologically) per $1 \mathrm{hpf}$ (high power field) as well as the percentage of RCAS1 and B7-H4-antigen immunopositive carcinoma cells were calculated. Macrophages and fibroblasts were evaluated in entire slides (at least $10 \mathrm{hpf}$ in each case).

The RCAS1 and B7-H4 expression in the cancer cells was graded as follows:

0 -lack of any positivity or expression in less than $1 \%$ of the cells; +1 -expression $1-10 \%$ of the carcinoma cells; +2 -positivity of $2-0 \%$ of the carcinoma cells; +3-expression in more than $50 \%$ of the carcinoma cells.

\section{Statistical Analysis}

The distribution of variables in the study groups of the patients checked with the use of the Shapiro-Wilk test showed that each of the patients was, in fact, different from normal. The statistical significance between the groups was determined by the Kruskal-Wallis test, one-way analysis of variance by ranks. The Mann-Whitney $U$ test was then used as applicable. All statistical analyses were carried out with the Statistica 8.0 software program. A p-value $<0.05$ was considered indicative of statistical significance.

\section{Results and Discussion}

\section{RCAS1}

RCAS1-immunopositive cancer cells were identified in $65 \%$ of the examined tissue samples of squamous cell carcinoma of the palatine tonsils. RCAS1-immunopositive macrophages were found in $40 \%$ of examined tissue samples of the cancer microenvironment. Statistically, significantly higher levels of RCAS1 was identified in cancer than in the microenvironment $(p<0.05)$ (Table 3). Statistically, significantly higher levels of RCAS1 immunoreactivity were detected in the cancer microenvironment of patients with the presence of lymph node metastases than in patients without such metastases $(p<0.05)$ (Table 4). Statistically significantly higher RCAS1 immunoreactivity levels were found in

Table 3. The levels of B7H4, RCAS1 and CD68 antigens immunoreactivity in carcinoma and stroma

\begin{tabular}{lccc}
\hline Antigen & $\begin{array}{c}\text { Cancer-squamous cell carcinoma } \\
\text { of the palatine tonsils }\end{array}$ & Stroma & p-value \\
\hline B7H4 & $2(2)$ & $1(0)$ & $<0.0001$ \\
RCAS1 & $2(1)$ & $0(0)$ & $<0.0001$ \\
CD68 & $1(1)$ & $2(2)$ & $<0.0001$ \\
\hline
\end{tabular}

Table 4. The levels of B7H4, RCAS1 and CD68 antigens immunoreactivity in patients with respect to the presence of lymph node metastases

\begin{tabular}{|c|c|c|c|}
\hline Antigen & $\begin{array}{c}\text { No }(n=24) \\
\text { Median } \\
(\text { O3-Q1) }\end{array}$ & $\begin{array}{c}N+(n=6) \\
\text { Median } \\
(\text { O3-Q1) }\end{array}$ & $\mathrm{p}$-value \\
\hline $\begin{array}{l}\text { Tumor } \\
\text { B7H4 }\end{array}$ & $2(1)$ & $2(2)$ & 0.01 \\
\hline Stroma Macrophages B7H4 & $0(1)$ & $1(1)$ & 0.04 \\
\hline Stroma Fibroblasts B7H4 & $0(0)$ & $1(1)$ & $p<0.001$ \\
\hline $\begin{array}{l}\text { Tumor } \\
\text { RCAS1 }\end{array}$ & $1(1)$ & $2(1)$ & $p<0.001$ \\
\hline Stroma Macrophages RCAS1 & $0(0)$ & $0(1)$ & 0.01 \\
\hline
\end{tabular}


Table 5. The levels of $\mathrm{B} 7 \mathrm{H} 4, \mathrm{RCAS} 1$ and $\mathrm{CD} 68$ with respect to the tumour grade

\begin{tabular}{lccc}
\hline Antigen & $\begin{array}{c}\text { G1 }+\mathbf{G 2}(\mathbf{n}=\mathbf{2 0}) \\
\text { Median } \\
(\mathbf{O 3 - Q 1 )}\end{array}$ & $\begin{array}{c}\text { G3 }(\mathbf{n}=\mathbf{1 0}) \\
\text { Median } \\
\mathbf{( 0 3 - Q 1 )}\end{array}$ & p-value \\
\hline $\begin{array}{l}\text { Tumor } \\
\text { B7H4 }\end{array}$ & $2(2)$ & $2(2)$ & NS \\
Microenvironment Macrophages B7H4 & $0(1)$ & $0(1)$ & NS \\
Microenvironment Fibroblasts B7H4 & $0(0)$ & $0(0)$ & NS \\
Tumor & $1(1)$ & $2(1)$ & p \\
RCAS1 & $0(0)$ & 001 & NS \\
Microenvironment Macrophages RCAS1 & & &
\end{tabular}

Table 6. The levels of $\mathrm{B} 7 \mathrm{H} 4, \mathrm{RCAS} 1$ and $\mathrm{CD} 68$ with respect to the tumour size

\begin{tabular}{lccc}
\hline Antigen & $\begin{array}{c}\text { T1 }+ \text { T2 }(\mathbf{n}=\mathbf{2 1}) \\
\text { Median } \\
\text { (O3-Q1) }\end{array}$ & $\begin{array}{c}\text { T3 + T4 }(\mathbf{n}=\mathbf{9}) \\
\text { Median } \\
(\mathbf{O 3 - Q 1})\end{array}$ & p-value \\
\hline $\begin{array}{l}\text { Tumor } \\
\text { B7H4 }\end{array}$ & $2(2)$ & $2(2)$ & NS \\
Microenvironment Macrophages B7H4 & $0(1)$ & $0(1)$ & NS \\
Microenvironment Fibroblasts B7H4 & $0(0)$ & $0(0)$ & NS \\
Tumor & $1(1)$ & $2(2)$ & p \\
RCAS1 & $0(0)$ & $0(0)$ & NS \\
Microenvironment Macrophages RCAS1 & & &
\end{tabular}

the tumour microenvironment of patients with G3 tumours than in those patients with G1 and G2 tumours $(p<0.05)$ (Table 5). Moreover, statistically, significantly higher RCAS1 immunoreactivity levels were identified in the tumour microenvironment of patients with T3 and T4 tumours than in those patients with T1 and T2 tumours $(p<0.05)$ (Table 6). Furthermore, a statistically significantly higher number of RCAS1-immunopositive macrophages in the tumour microenvironment were detected in patients with the presence of lymph node metastases $(p<0.05)$ (Table 4).

\section{$\mathrm{B} 7 \mathrm{H} 4$}

B7-H4-positive cancer cells were identified in all the tissue samples of palatine tonsil squamous cell carcinoma. Within the cancer microenvironment, B7$\mathrm{H} 4$ immunopositive macrophages were found in $60 \%$ of the cases, and B7-H4 immunopositive fibroblasts in $85 \%$ of the cases. Statistically, significantly higher levels of B7-H4 immunoreactivity in the tumour were identified in patients with the presence of lymph node metastases than in those patients without such metastases. No statistically significant differences were identified between B7-H4 immunoreactivity levels and the tumour grade and size. A statistically significantly higher number of B7-H4-positive cancer-associated fibroblasts and macrophages was identified in those patients with the presence of lymph node metastases $(p<0.05)$. No statistically significant differences, however, were found between the B7-H4 immunoreactivity levels in cancer-associated fibroblasts and macrophages and the tumour size and grade.

\section{CD68}

CD68 immunopositive cells were identified in all the cancerous tissue samples and their tumour microenvironments. Statistically significantly higher number of CD68 positive cells was identified in the stroma than in cancer samples. No statistically significant differences were identified between the number of CD-68 immunopositive cells and the clinicopathological parameters, including tumour size, tumour grade, and lymph node status (Table 3 ).

In the reference group of chronic tonsillitis tissue samples, an intensive $\mathrm{B} 7 \mathrm{H} 4$ antigen immunoreactivity was observed in the epithelium of the palatine crypts (Figure 1A), but the surface epithelium of the palatine tonsils did not demonstrate B7-H4 antigen immunoreactivity (Figure 1B). Single cells within the tonsillar lymphatic nodules and intramodular space also demonstrated B7-H4 antigen immunoreactivity (Figure 2). These cells were identified as macrophages. 

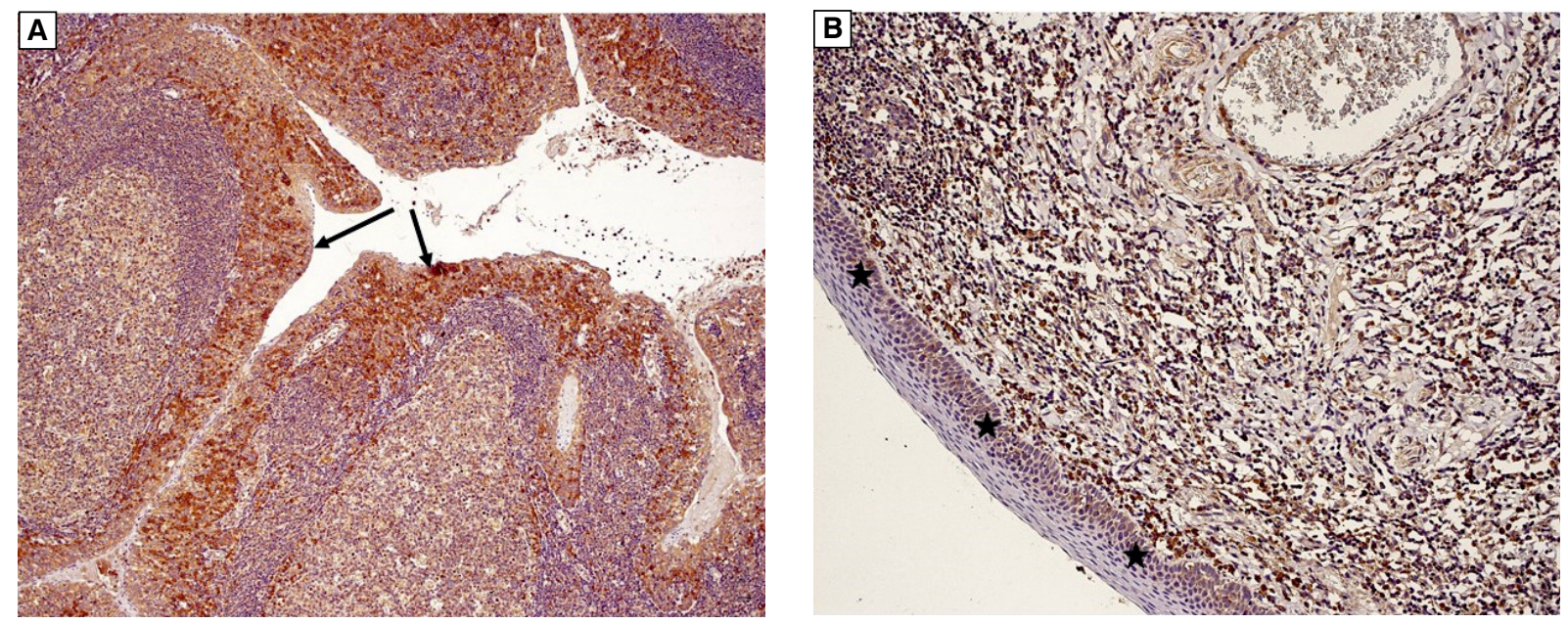

Figure 1. An intensive $\mathrm{B} 7 \mathrm{H} 4$ antigen immunoreactivity in the epithelium of tonsillar crypts in chronic tonsillitis (arrows) and no B7H4 antigen immunoreactivity in the surface epithelium (stars) of the palatine tonsil. Magnification A-40x, B-20x
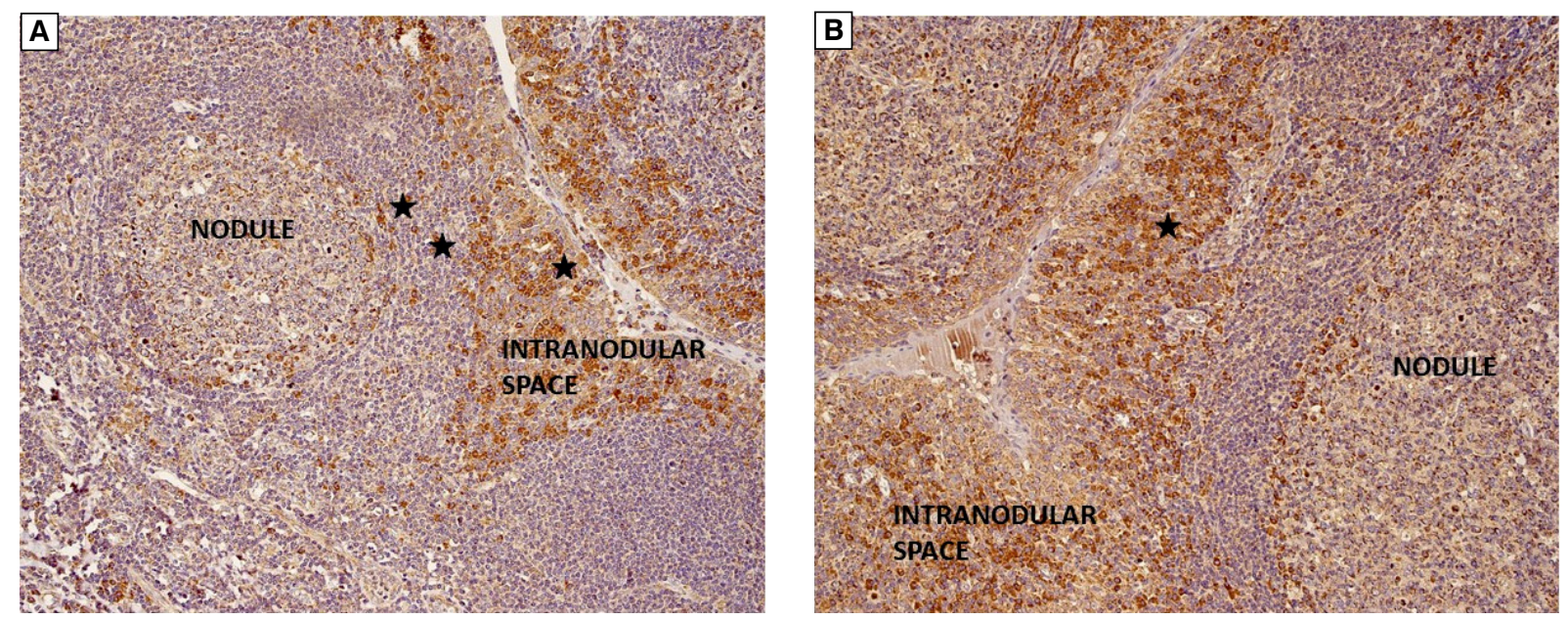

Figure 2. Scattered cells (macrophages) with $\mathrm{B} 7 \mathrm{H} 4$ antigen immunoreactivity in tonsillar nodules and in intramodular space (stars). Magnification A-20x, B-40x

In the present study, we have shown that the B7$\mathrm{H} 4$ antigen was over-expressed in cancerous tonsillar tissue and was significantly higher in those patients with the presence of lymph node metastases. The immunoreactivity of $\mathrm{B} 7-\mathrm{H} 4$ in the cancerous tumour microenvironment was represented by macrophages and cancer-associated fibroblasts and was statistically significantly associated with the presence of lymph node metastases. The results presented remain in agreement with the study concerning oral squamous cell carcinoma, where $\mathrm{B} 7-\mathrm{H} 4$ antigen expression was significantly associated with pathological grade and lymph node status. Moreover, it was demonstrated that patients with high $\mathrm{B} 7-\mathrm{H} 4$ expression had poorer overall survival compared with those with low B7$\mathrm{H} 4$ expression, and it was suggested that $\mathrm{B} 7-\mathrm{H} 4$ could be a potential target in the treatment of oral squamous cell carcinoma [12]. All these findings suggest that B7-H4 antigen immunoreactivity by tonsillar cancer cells and microenvironment macrophages, together with cancer-associated fibroblasts, are related to the potential to develop metastases. In a meta-analysis, it was demonstrated that elevated $\mathrm{B} 7-\mathrm{H} 4$ is an independent predictor of poorer overall survival in patients with solid tumours [21]. In ovarian cancer, Kryczek et al. have determined that ovarian cancer cells and tumour-associated macrophages express $\mathrm{B} 7-\mathrm{H} 4$ and inhibit TAA-specific T-cell proliferation, cytokine production, and cytotoxicity [7]. The intensity of the B7$\mathrm{H} 4$ expression of the macrophages was associated with tumour-infiltrating Treg cells and negatively predicted patient survival. 
The studies on B7-H4 antigen over-expression in cancer cells and in the tumour microenvironment suggest that $\mathrm{B} 7-\mathrm{H} 4$ over-expression reflects the growing resistance to the immune response by various mechanisms. It has been shown that $\mathrm{B} 7-\mathrm{H} 4$ plays an important role in inhibiting CD4-positive and CD8-positive cell proliferation [22]. Chen et al. have demonstrated that B7-H4 participates in inducing cytotoxic lymphocyte apoptosis in patients with Lewis lung carcinoma [8]. B7-H4 stimulation was observed to induce cell cycle arrest in different phases and inhibited T-cells [22]. B7-H4 inhibited cytokine production and cytotoxicity of T cells [22]. Cancer-associated B7-H4 was resistant to T-cell mediated cytotoxic activity [23]. Various studies have recently demonstrated that the blockade of cancer-associated B7-H4 may enhance T-cell-mediated antitumor immunity, and this knowledge could lead to the formulation of a new therapeutic strategy for cancer treatment [9, 24-25, 26-29].

In the present study, B7-H4 antigen immunoreactivity was also observed in the palatine tonsils taken from patients with chronic tonsillitis. Immunoreactivity was detected in the epithelium of tonsillar crypts and in the macrophages of lymph nodules as well as in intramodular spaces. The results confirmed that B7$\mathrm{H} 4$ has an important immunoregulatory role and that the region of stratified crypt epithelium, along with the lymph nodules and intramodular space in the palatine tonsils, is responsible for direct contact with antigens and the regulation of the immune response.

In the present study, RCAS1 antigen over-expression was identified in palatine tonsil squamous cell carcinoma cells and associated with the presence of lymph node metastases. RCAS1 is a poor prognostic factor in cases involving 15 different types of cancers [17]. In the present study, the number of RCAS1-immunopositive macrophages in the cancer microenvironment was significantly associated with the presence of lymph node metastases. Similarly, Sonoda et al. have observed that RCAS1 expression in the tumour microenvironment correlates with the potential to develop metastases. In our earlier reports on head and neck (pharyngeal and laryngeal) cancer, RCAS1 over-expression in both a tumour and in the tumour microenvironment was also associated with the potential to develop metastases, confirming that RCAS1 is an indicator of poor prognosis in these tumors $[2,17,20]$.

\section{Conclusion}

Our study seems to indicate that both RCAS1- and B7-H4- immunopositive macrophages, together with B7H4 immunopositive cancer-associated fibroblasts, may play an important role in creating the suppressive profile of the tumour microenvironment of patients with tonsillar cancer. Furthermore, it also seems to show that the over-expression of $\mathrm{B} 7-\mathrm{H} 4$ in the microenvironment plays a significant role in promoting tumour progression and metastases. We have thus concluded that B7H4 may be an important factor in immune evasion in patients with tonsillar cancer. It would also seem to constitute a new target for immunotherapy in such patients.

\section{References}

1. Hanahan D, Weinberg RA. Hallmarks of cancer: the next generation. Cell. 2011; 144(5): 646-674, doi: 10.1016/j.cell.2011.02.013, indexed in Pubmed: 21376230

2. Dutsch-Wicherek M, Lazar A, Tomaszewska R, et al. Analysis of metallothionein and vimentin immunoreactivity in pharyngeal squamous cell carcinoma and its microenvironment. Cell Tissue Res. 2013; 352(2): 341349, doi: 10.1007/s00441-013-1566-1, indexed in Pubmed: 23397427.

3. Galazka K, Opławski M, Windorbska W, et al. The immunohistochemical analysis of antigens such as RCAS1 and B7H4 in the cervical cancer nest and within the fibroblasts and macrophages infiltrating the cancer microenvironment. Am J Reprod Immunol. 2012; 68(1): 85-93, doi: 10.1111/j.1600-0897.2012.01134.x, indexed in Pubmed: 22530960.

4. Dutsch-Wicherek M. RCAS1, MT, and vimentin as potential markers of tumor microenvironment remodeling. Am J Reprod Immunol. 2010; 63(3): 181-188, doi: 10.1111/j.1600-0897.2009.00803.x, indexed in Pubmed: 20085563.

5. Jozwicki W, Windorbska W, Brozyna AA, et al. The analysis of receptor-binding cancer antigen expressed on SiSo cells (RCAS1) immunoreactivity within the microenvironment of the ovarian cancer lesion relative to the applied therapeutic strategy. Cell Tissue Res. 2011; 345(3): 405-414, doi: 10.1007/s00441-011-1216-4, indexed in Pubmed: 21845402

6. Pollard JW. Tumour-educated macrophages promote tumour progression and metastasis. Nat Rev Cancer. 2004; 4(1): 71-78, doi: 10.1038/nrc1256, indexed in Pubmed: 14708027.

7. Kryczek I, Wei S, Zhu G, et al. Relationship between B7-H4, regulatory $\mathrm{T}$ cells, and patient outcome in human ovarian carcinoma. Cancer Res. 2007; 67(18): 8900-8905, doi: 10.1158/0008-5472.CAN-07-1866, indexed in Pubmed: 17875732

8. Chen C, Qu QX, Shen Yu, et al. Induced expression of B7-H4 on the surface of lung cancer cell by the tumor-associated macrophages: a potential mechanism of immune escape. Cancer Lett. 2012; 317(1): 99-105, doi: 10.1016/j.canlet.2011.11.017, indexed in Pubmed: 22108530.

9. Sica GL, Choi InH, Zhu G, et al. B7-H4, a molecule of the B7 family, negatively regulates T cell immunity. Immunity. 2003; 18(6): 849-861, indexed in Pubmed: 12818165

10. Zang X, Loke P, Kim J, et al. B7x: a widely expressed B7 family member that inhibits T cell activation. Proc Natl Acad Sci U S A. 2003; 100(18): 10388-10392, doi: 10.1073/pnas.1434299100, indexed in Pubmed: 12920180

11. Prasad DVR, Richards S, Mai XM, et al. B7S1, a novel B7 family member that negatively regulates T cell activation. Immunity. 2003; 18(6): 863-873, indexed in Pubmed: 12818166.

12. Wu L, Deng WW, Yu GT, et al. B7-H4 expression indicates poor prognosis of oral squamous cell carcinoma. Cancer Immunol Immunother. 2016; 65(9): 1035-1045, doi: 10.1007/s00262-016-1867-9, indexed in Pubmed: 27383830

13. Sonoda K, Nakashima M, Kaku T, et al. A novel tumor-associated antigen expressed in human uterine and ovarian carcinomas. Cancer. 1996; 77(8): 1501-1509, doi: 10.1002/(SICl)1097-0142(19960415)77:8 < 1501::AID-CNCR12>3.0.CO:2-3, indexed in Pubmed: 8608535.

14. Sonoda K, Miyamoto S, Hirakawa T, et al. Clinical significance of RCAS1 as a biomarker of uterine cancer. Gynecol Oncol. 2006; 103(3): 924931, doi: 10.1016/j.ygyno.2006.05.047, indexed in Pubmed: 16842844.

15. Sonoda K, Miyamoto S, Hirakawa T, et al. Invasive potency related to RCAS1 expression in uterine cervical cancer. Gynecol Oncol. 2005; 99(1): 189-198, doi: 10.1016/j.ygyno.2005.06.061, indexed in Pubmed: 16112176

16. Sonoda K, Miyamoto S, Kobayashi H, et al. The level of RCAS1 expression is inversely correlated with the number of vimentin-positive stromal cells in epithelial ovarian cancer. Int J Gynecol Cancer. 2009; 
19(5): 838-843, doi: 10.1111/IGC.0b013e3181a5ff6a, indexed in Pubmed: 19574770.

17. Sonoda K, Miyamoto S, Nakashima M, et al. The biological role of the unique molecule RCAS1: a bioactive marker that induces connective tissue remodeling and lymphocyte apoptosis. Front Biosci. 2008; 13 : 1106-1116, indexed in Pubmed: 17981616.

18. Kokkinos MI, Wafai R, Wong MK, et al. Vimentin and epithelial-mesenchymal transition in human breast cancer--observations in vitro and in vivo. Cells Tissues Organs. 2007; 185(1-3): 191-203, doi: 10.1159/000101320, indexed in Pubmed: 17587825.

19. Dutsch-Wicherek $M$, Tomaszewska $R$, Lazar $A$, et al. The association between RCAS1 expression in laryngeal and pharyngeal cancer and its healthy stroma with cancer relapse. BMC Cancer. 2009; 9: 35, doi: 10.1186/1471-2407-9-35, indexed in Pubmed: 19175908

20. Dutsch-Wicherek M, Kazmierczak W. Creation of a suppressive microenvironment by macrophages and cancer-associated fibroblasts. Front Biosci (Landmark Ed). 2013; 18: 1003-1016, indexed in Pubmed: 23747863.

21. Song X, Shao Y, Gu W, et al. Prognostic role of high B7-H4 expression in patients with solid tumors: a meta-analysis. Oncotarget. 2016; 7(47): 76523-76533, doi: 10.18632/oncotarget.8598, indexed in Pubmed: 27058425.

22. Wang $X$, Hao J, Metzger DL, et al. B7-H4 Treatment of T Cells Inhibits ERK, JNK, p38, and AKT Activation. PLoS One. 2012;
7(1): e28232, doi: 10.1371/journal.pone.0028232, indexed in Pubmed: 22238573

23. Abadi YM, Jeon H, Ohaegbulam KC, et al. Host b7x promotes pulmonary metastasis of breast cancer. J Immunol. 2013; 190(7): 3806-3814, doi: 10.4049/jimmunol.1202439, indexed in Pubmed: 23455497.

24. Xu Y, Zhu S, Song M, et al. B7-H4 expression and its role in interleukin-2/interferon treatment of clear cell renal cell carcinoma. Oncol Lett. 2014; 7(5): 1474-1478, doi: 10.3892/ol.2014.1961, indexed in Pubmed: 24765159

25. Zhu $\mathrm{Q}$, Xiong $\mathrm{H}$, Azimu $\mathrm{S}$, et al. Expression of $\mathrm{B} 7-\mathrm{H} 4$ and gastric cancer progression and prognosis: a meta-analysis. Int $\mathrm{J}$ Clin Exp Med. 2016; 9: 15185-90.

26. Leong SR, Liang WC, Wu Y, et al. An anti-B7-H4 antibody-drug conjugate for the treatment of breast cancer. Mol Pharm. 2015; 12(6): 1717-1729, doi: 10.1021/mp5007745, indexed in Pubmed: 25853436.

27. Smith JB, Lanitis E, Dangaj D, et al. Tumor Regression and Delayed Onset Toxicity Following B7-H4 CAR T Cell Therapy. Mol Ther. 2016; 24(11): 1987-1999, doi: 10.1038/mt.2016.149, indexed in Pubmed: 27439899

28. Dangaj D, Scholler N. Isolation and Validation of Anti-B7-H4 scFvs from an Ovarian Cancer scFv Yeast-Display Library. Methods Mol Biol. 2015; 1319: 37-49, doi: 10.1007/978-1-4939-2748-7 2, indexed in Pubmed: 26060068.

29. Liang Li, Jiang Yi, Chen JS, et al. B7-H4 expression in ovarian serous carcinoma: a study of 306 cases. Hum Pathol. 2016; 57: 1-6, doi: 10.1016/j.humpath.2016.06.011, indexed in Pubmed: 27349304. 